LA-UR- $96-643$

Title: Dual-Rod Cr:LISAF Osc1llator/Amplifier for

Remote Sensing Applications

Author(s):

James W. Early, Charles S. Lester, Nigel J. Cockroft, Christyl C. Johnson, Donald J. Relchle, and David W. Mordaunt

Submitted to:

Proceedings of Advanced Solid State Lasers OSA Meeting, January 29-February 2, 1996, San Franclsco, CA. To be published in Optics \& Photonics.

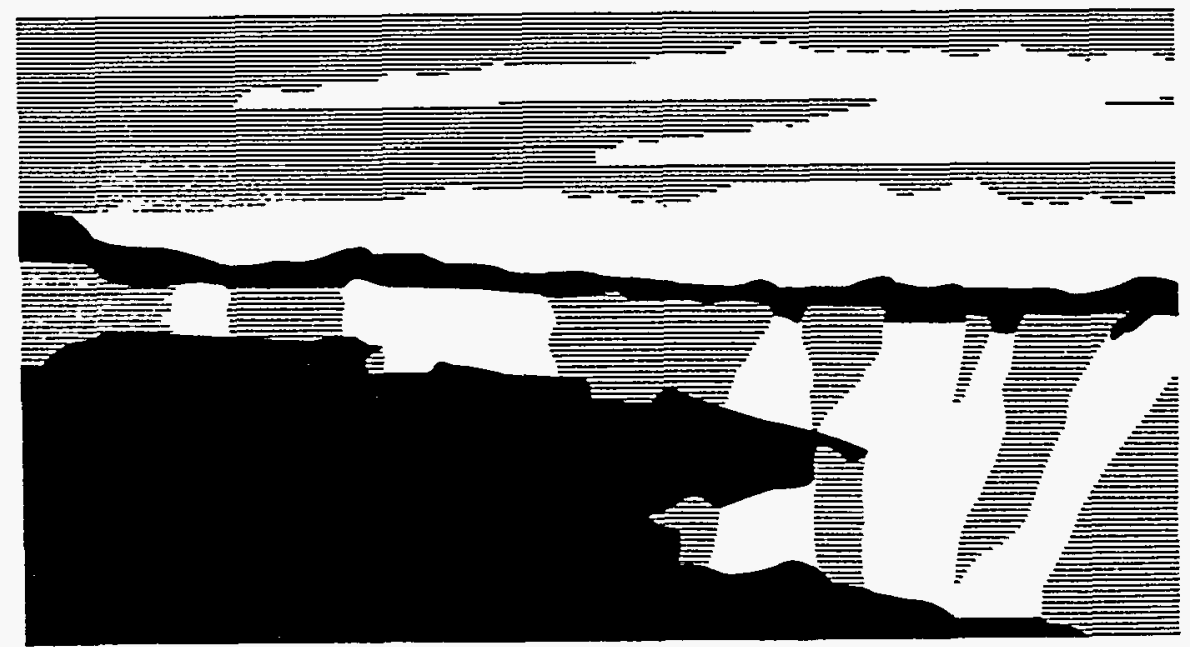

Los Alamos National Laboratory, an affirmative action/equal opportunity empldyer, is operated by the University of California lor the U.S. Department of Energy

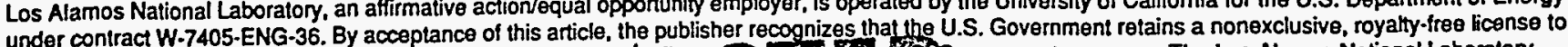

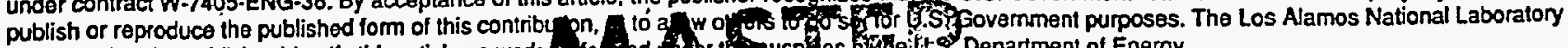

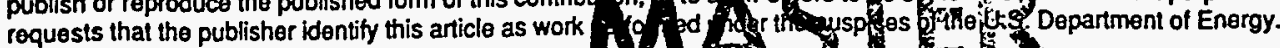




\title{
Dual-rod Cr:LiSAF oscillator/amplifier for remote sensing applications
}

\author{
James W. Early, Charles S. Lester and Nigel J. Cockroft \\ Chemical Science and Technology Division \\ Los Alamos National Laboratory, MS E535 \\ Los Alamos, NM 87545 \\ Christyl C. Johnson and Donald J. Reichle \\ NASA Langley Research Center \\ Hampton, VA 23681 \\ David W. Mordaunt* \\ Stratonics, Inc. \\ 4 Jenner Street, Suite 190 \\ Irvine, $\mathrm{CA} 92718$
}

\begin{abstract}
A dual rod configuration is used to achieve $16 \mathrm{~W}$ average power operation from a flashlamp-pumped $\mathrm{Cr}$ :LiSAF laser oscillator. A double-pass dual-rod amplifier configuration was used to amplify $141 \mu \mathrm{J}$ pulses from a Q-switched diode-pumped LiSAF oscillator by a factor of $\sim 120$. This experiment established a small signal gain of $13.4 \%$ per $\mathrm{cm}$ at 820 $\mathrm{nm}$. Improved slope efficiency (7.4\% electrical-tolight) and pulse repetition frequency $(40 \mathrm{~Hz})$ were achieved with a single-rod oscillator using improved $\mathrm{Cr}:$ LiSAF material.
\end{abstract}

Key Words: Rare-earth and transition metal solid state lasers, Lidar.

\section{Introduction}

Chromium-doped LiSAF has many attributes desirable for remote sensing lidar applications. The broad tunability $(0.78-1 \mu \mathrm{m})$ [1-2], especially in combination with nonlinear harmonic generation to the visible and ultraviolet regions, has broad potential for speciesspecific measurement techniques. A long fluorescence lifetime $(67 \mu \mathrm{sec})$ enables good energy storage and high Q-switched pulse energy desirable for long range lidar measurement. Broad absorption bands in the red, blue and UV enable very efficient coupling of flashlamp excitation or $670 \mathrm{~nm}$ diode-laser pump energy. Los Alamos National Laboratory (LANL) and NASA Langley Research Center (LaRC) have been developing the tunable $\mathrm{Cr}$ :LiSAF laser system for lidar applications. Recent demonstrations at LANL using dual-lamp excitation of a single laser rod have achieved average power output of 11 Watts with pulse energy exceeding 3 Joules for normal-mode $(20-30 \mu \mathrm{sec}$ long pulses) and Q-switched pulse energies of $0.45 \mathrm{~J}$ (23 nsec pulses) [3]. The system has been used to perform high-resolution water-vapor DIAL measurements and metal-ion fluorescence measurements. The configuration giving the highest quality results was a Littman grating-cavity design that provided continuous tunability over a broad spectral range with a linewidth of $2 \mathrm{GHz}$ [4]. NASA LaRC have developed a $680 \mathrm{~nm}-$ diode-pumped LiSAF oscillator with greater than $30 \mathrm{~mJ}$ and $2.5 \mathrm{~mJ}$ energy for normal mode and Q-switched mode pulses, respectively. [5]

One of the difficulties experienced in the LiSAF lidar transmitter development has been the occurrence of thermally-induced microstructure damage at an average electrical power to the lamps of $480-500 \mathrm{~W}$ (for a $1 / 4^{\prime \prime}(0.635 \mathrm{~cm}) \times 10 \mathrm{~cm}$ rod) [3]. Results to date led us to conclude that the intrinsic thermo-mechanical limitations of LiSAF can best be overcome by the use of a dual-rod gain configuration. We report results of the evaluation of a dual-rod design for both amplifier and oscillator applications and also improved benchmarks for single-rod laser oscillation.

\section{Single-rod oscillator}

Cr:LiSAF rods have been commercially available for several years. During the past year the product has been further refined by research at Lightning Optical Corporation under a NASA SBIR program. Scattering loss has been reduced to less than $0.1 \%$ per $\mathrm{cm}$ and rods are now mined from defect and stress-free regions as determined by an interferometric imaging technique. [6]

The normal-mode laser performance of a $7 \mathrm{~mm}$ diameter $\times 10 \mathrm{~cm}$ long $1.5 \% \mathrm{Cr}$ : LiSAF rod of the new material is characterized in Figure 1. A dual-Xenonflashlamp, diffuse-reflectivity, close-coupled pump head was powered with a $60 \mu \mathrm{sec}$ (FWHM) current pulse. The resonator cavity comprised a $2 \mathrm{~m}$ radius-ofcurvature dielectric high reflector and a flat output coupler separated by $61 \mathrm{~cm}$. The $7.4 \%$ slope efficiency 
for the $60 \%$ reflectivity output coupler is a significant improvement over the $4.8 \%$ value obtained in the same cavity for a $1 / 4$ " $(6.35 \mathrm{~mm}) \times 10 \mathrm{~cm}$ rod, of previous generation (approximately 18 months old) material, shown for comparison in Figure 1. The improved performance for the $7 \mathrm{~mm}$ rod may also be partially due to increased pump-head coupling efficiency for the larger rod.

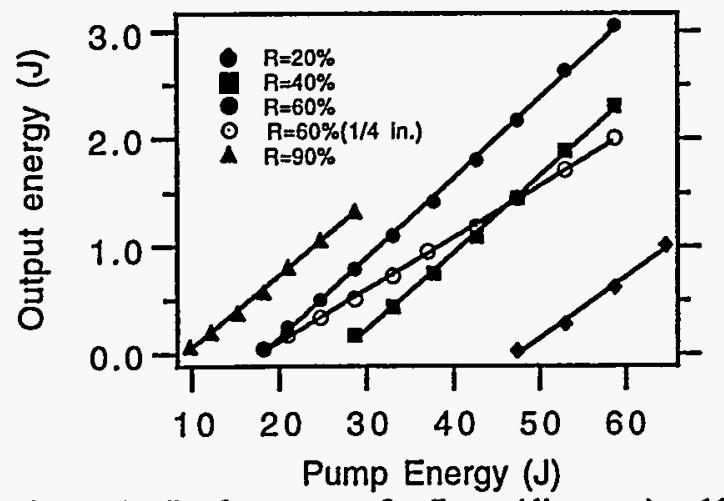

Figure 1. Performance of a $7 \mathrm{~mm}$ (diameter) $\times 10 \mathrm{~cm}$ (long) laser rod for various values ofoutput coupler reflectivity. Performance of a $1 / 4$ in. rod in the same (60\% reflectivity) cavity is shown for comparison.

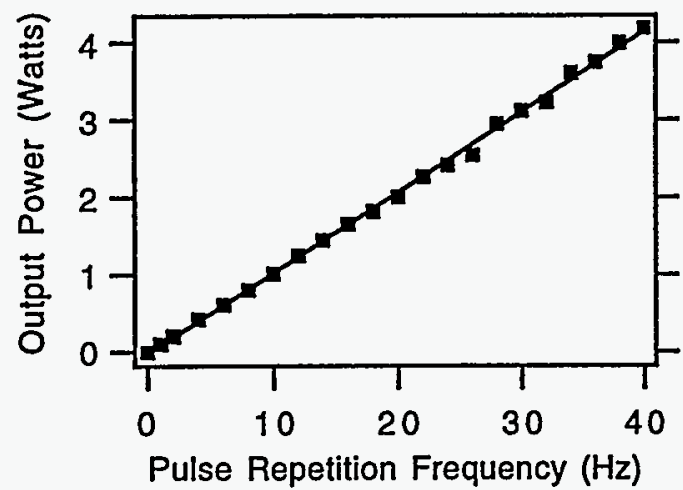

Figure 2. High PRF performance of a $7 \mathrm{~mm}$ (diameter) $x 10 \mathrm{~cm}$ (long) rod in normal mode operation. Electrical pump energy is $10.2 \mathrm{~J}$ and output coupler reflectivity is $90 \%$.

The pump energy required for lasing threshold of the new rod was also reduced. This enabled operation at low pump energy in a high-reflectivity cavity at high pulse repetition frequency (PRF). Figure 2 shows operation of the laser at $40 \mathrm{~Hz}$, the highest PRF attempted, with $\sim 100 \mathrm{~mJ}$ per pulse using a $90 \%$ reflectivity output coupler. Figure 2 shows no evidence of thermal lensing or damage effects. The absence of thermal lensing effects at this high pump average power $(408 \mathrm{~W})$ is noteworthy since previous studies with comparable cavities using rods of the earlier type had shown a "roll over" in average output power when pump power exceeded approximately $330 \mathrm{~W}$. This may be indicative of a defect and-stress related dependence of the thermo-optic properties. At $40 \mathrm{~Hz}$ the pump power is $45 \mathrm{~W} / \mathrm{cm}$, slightly below the $53 \mathrm{~W} / \mathrm{cm}$ damage threshold known from study of the previous generation material [3]. It is not yet known if the thermal damage threshold of the latest material has increased.

\section{Dual-rod oscillator}

Ten-cm-long $1.5 \% \mathrm{Cr}$ doped LiSAF rods of diameter $1 / 4$ inch and $7 \mathrm{~mm}$ were configured in identical duallamp pump heads in a linear oscillator cavity of length $61 \mathrm{~cm}$, with a $2 \mathrm{~m}$ radius of curvature high reflector and a flat dielectric output coupler. The slope efficiencies for operation of each of the rods separately (with the other head remaining in the cavity) were $5.6 \%$ and $3.3 \%$ for the $7 \mathrm{~mm}$ and $1 / 4$ " rods respectively. The reduction of these efficiencies relative to those of Figure 1 is attributed to aperture diffraction losses for the dual rod configuration, an effect that could be addressed by appropriate engineering design.

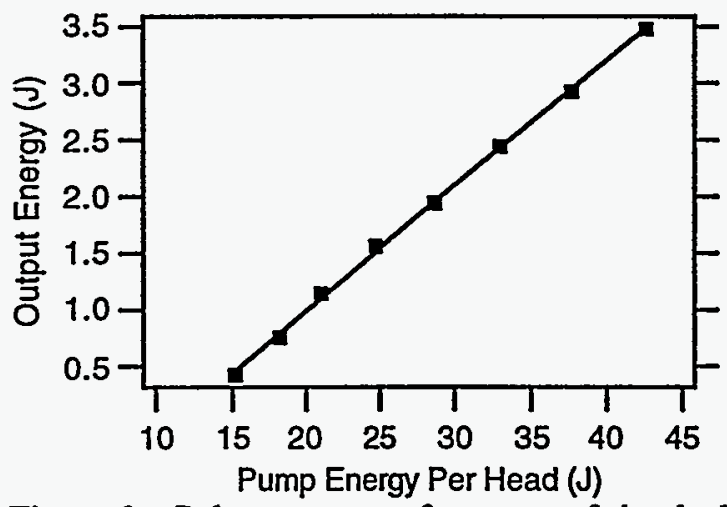

Figure 3. Pulse energy performance of the dual rod oscillator at $1 \mathrm{~Hz}$ as a function of the pump energy delivered to each head. Output coupler reflectivity is $60 \%$.

Figure 3 shows the output characteristics of this configuration as a function of electrical energy delivered to each of the two heads simultaneously. The purpose for using the dual-rod design was to increase average power operation while avoiding thermomechanical damage by requiring less pump energy in each rod to obtain a desired pulse energy. Comparison of Figures 1 and 3 confirm this advantage. In fact, for a given input energy level, the output energy exceeds the sum of the output for the two heads when operating separately within the dual-head cavity. 
Figure 4 shows operation of the dual-rod oscillator up to $16 \mathrm{~W}$ output at $10 \mathrm{~Hz}$, with no apparent thermal lensing effects. This situation corresponds to a pump excitation power of only $290 \mathrm{~W}$ per rod. For the same pump-pulse energy damage is not expected to occur until $16-18 \mathrm{~Hz}$ operation giving output powers on the order of $35 \mathrm{~W}$ (neglecting thermal lensing losses). Other pulse energy/ PRF combinations were evaluated up to $20 \mathrm{~Hz}$ operation which gave $7.8 \mathrm{~W}$ average power for $15 \mathrm{~J} /$ pulse input.

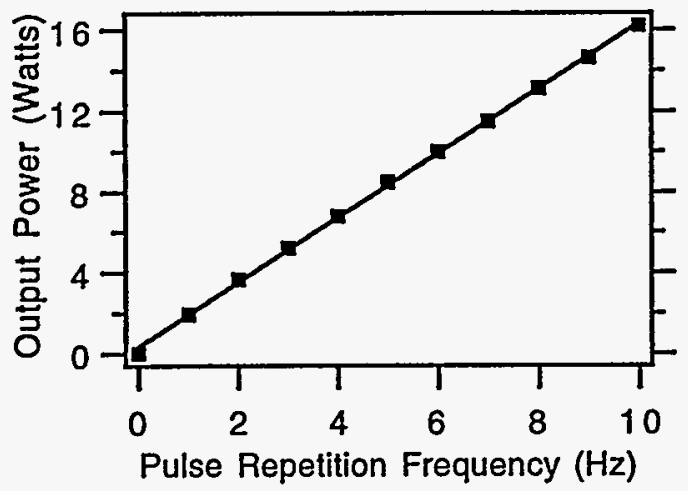

Figure 4. Output power of the dual-rod oscillator for an electrical pump energy of $28.7 \mathrm{~J}$ per head.

Significantly higher output powers are expected at high PRFs for configurations with lower output coupling.

\section{Dual-rod amplifier}

The red absorption bands of Cr:LiSAF are ideal for GaInP/ AlGaInP diode laser pumping in the 670-690 $\mathrm{nm}$ region. NASA LaRC are developing a diodepumped oscillator system for LIDAR applications. Motivated by interest in the near-term evaluation of the feasibility of long range temperature measurement using diode-pumped Cr:LiSAF-based water-vapor DIAL, we performed the integration of the diodepumped Cr:LiSAF oscillator with a dual-rod, doublepass, flashlamp-pumped amplifier.

The oscillator, described in detail elsewhere [5], comprised three $680 \mathrm{~nm}$ diode stacks (up to $60 \mathrm{~mJ}$ each) sidepumping a $1 \mathrm{~cm} 1.5 \%$ Cr:LiSAF rod. This configuration delivers up to $30 \mathrm{~mJ}$ in normal pulse mode and $2.5 \mathrm{~mJ}$ when Q-switched. In Q-switched mode the pulses were approximately $200 \mathrm{nsec}$ long. For this study the oscillator was successfully injection seeded by a tunable diode laser with linewidth less than $2 \mathrm{Mhz}$. A $5 \mathrm{~mW}$ New Focus external cavity laser and a $75 \mathrm{~mW}$ injection-current tuned AlGaAs diode were each used to successfully seed the cavity. A single plate birefringent filter was used in the cavity to center the gain curve on water vapor lines around $820 \mathrm{~nm}$.

The Q-switched output from the oscillator was double-passed through two $7 \mathrm{~mm} \times 10 \mathrm{~cm}$ long rods in a linear chain. The first of these rods had been damaged before this experiment and exhibited a significantly greater scattering loss than the other. After the first pass the beam was reflected with a flat dielectric high reflector mirror and the beam was extracted from the amplifier using a polarizing cube on a Faraday Isolator at the amplifier input/output end. Each rod was pumped with dual Xenon flashlamps driven by a $60 \mu \mathrm{sec}$ (FWHM) electrical pulse. The various isolation stages and prism coupling used for injection seeding and for amplifier injection, along with the damage in one of the amplifier rods resulted in quite high overall loss through the system. For example a pulse energy of $1.27 \mathrm{~mJ}$ leaving the oscillator corresponding to a double-pass throughput energy after the (non-powered) amplifier of $242 \mu \mathrm{J}$. Replacement of the damaged rod with pristine LiSAF (scatter loss less than $0.1 \% / \mathrm{cm}$ ) and the use of isolators and polarization couplers optimized for the $820 \mathrm{~nm}$ wavelength would greatly improve the throughput and output from this amplifier.

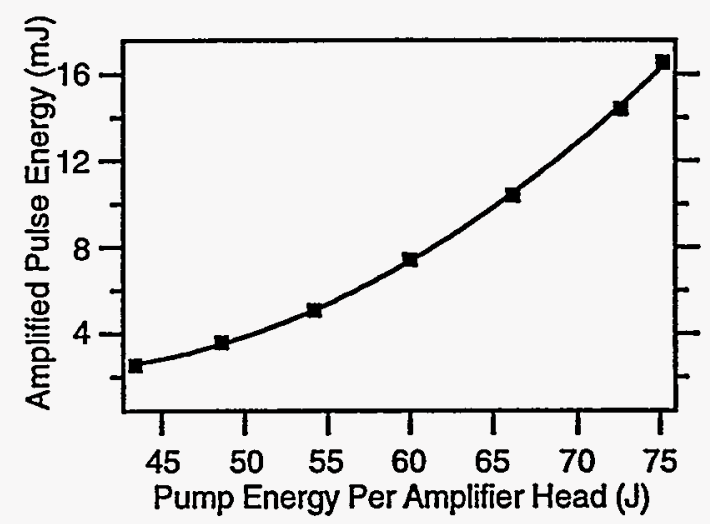

Figure 5. Performance of the dual-rod double-passed amplifier for amplification of $141 \mu \mathrm{J}$ pulses at $2 \mathrm{~Hz}$.

Despite the losses the amplifier performed extremely well. Most of the characterization of the amplifier was done for a Q-switched pulse energy through the (non-pumped) system of $141 \mu \mathrm{J}$. Figure 5 shows the amplified pulse energy as a function of the electrical energy delivered to each of the two heads simultaneously. The $16.7 \mathrm{~mJ}$ output for $75 \mathrm{~J}$ excitation corresponds to a signal amplification of 117.4 from which we establish a small signal gain of 0.134 per $\mathrm{cm}$. This value exceeds that expected, based on previous measurements on $6.35 \mathrm{~mm}$ rods [3], by approximately $10 \%$. The difference may be due to improved material 
quality or to better coupling efficiency of the lamps to the larger $(7 \mathrm{~mm})$ rods. Gain saturation was not evident for the $141 \mu \mathrm{J}$ pulse amplification or when the input was increased to the highest input energy tried $(242 \mu \mathrm{J})$. Because of it's high saturation energy $(\sim 7 \mathrm{~J} / \mathrm{cm} 2)$, amplification in Cr:LiSAF is expected to be linear with pulse input energy to high energy.

\section{Conclusion}

Cr:LiSAF appears to exhibit all of the attributes desired for an excellent tunable lidar transmitter. The most limiting system property has been the thermal damage limit which can be ameliorated by the dual-rod design. Use of two rods is also less expensive and more rugged than use of a single longer rod. An optimized cavity with new low-loss rods should operate up to approximately $30 \mathrm{~W}$ in normal mode at $10 \mathrm{~Hz}$. An optimized Q-switch is expected to enable Q-switched pulses exceeding $0.5 \mathrm{~J}$ at $10 \mathrm{~Hz}$, or lower energy pulses at much greater PRF. The latest generation of laser material is found to perform better than previous material.

\section{Acknowledgments}

This work was supported by the Department of Energy under Los Alamos National Laboratory's Directed Research and Development program, the DOE/LANL Small Business Initiative Technical Assistance Program and by NASA Langley Research Center.

* Dr Mordaunt is now at Sensors, Lasers and Research Center, TRW, One Space Park, Redondo Beach, CA 90278.

\section{References:}

[1] M. Stalder, B.H. Chai and M. Bass, Appl. Phys Lett. 58, 216 (1991)

[2] T. Ditmire and M.D. Perry, Opt. Lett. 18, 426 (1993)

[3] T. Shimada, J. W. Early, C.S. Lester and N.J. Cockroft, OSA Proceedings on Advanced Solid-State Lasers, 1994, pp 188-191, Vol 20, T.Y. Fan and B.H.T. Chai, editors.

[4] J. W. Early, C.S. Lester, C.R. Quick, J.J. Tiee, T. Shimada and N.J. Cockroft, OSA Proceedings on Advanced Solid-State Lasers, 1995, pp 9-12, Vol 24, B.H.T. Chai and S.A. Payne, editors.

[5] C.C. Johnson, D.J. Reichle, N.P. Barnes and G.J. Quarles, Paper WC4-1, OSA Advanced Solid-State Lasers Meeting, San Francisco, 1996.

[6] G.J. Quarles, Lightning Optical Corp, private communication.

\section{DISCLAIMER}

This report was prepared as an account of work sponsored by an agency of the United States Government. Neither the United States Government nor any agency thereof, nor any of their employees, makes any warranty, express or implied, or assumes any legal liability or responsibility for the accuracy, completeness, or usefulness of any information, apparatus, product, or process disclosed, or represents that its use would not infringe privately owned rights. Reference herein to any specific commercial product, process, or service by trade name, trademark, manufacturer, or otherwise does not necessarily constitute or imply its endorsement, recommendation, or favoring by the United States Government or any agency thereof. The views and opinions of authors expressed herein do not necessarily state or reflect those of the United States Government or any agency thereof. 